\title{
Earthquake Information Products and Tools from the Advanced National Seismic System (ANSS)
}

This Fact Sheet provides a brief description of postearthquake tools and products provided by ANSS through the U.S. Geological Survey Earthquake Hazards Program. The focus is on products specifically aimed at providing situational awareness in the period immediately following significant earthquake events.

\section{ANSS Background}

The Advanced National Seismic System (ANSS) is a partnership of the U.S. Geological Survey (USGS), academia, other government agencies, and industry that monitors earthquakes in the United States and collects seismic data. Since its inception in 2000, funding has provided for the installation of more than 700 new seismic stations to collect highquality seismic data to serve the needs of the emergency management and response, engineering, and scientific communities.

The Federal Emergency Management Agency (FEMA) has estimated the annualized earthquake losses in the United States to be $\$ 5.6$ billion per year, with a single earthquake potentially causing losses greater than $\$ 100$ billion. Such losses can be mitigated by using information from seismic monitoring to effectively focus resources in regions of significant risk, to perform seismic rehabilitation, to improve the overall performance of earthquake engineering designs, and to plan for the response to hazardous events.

In addition to these basic and fundamental scientific and hazard monitoring roles, a modern seismic system is vital for providing timely and accurate information about earthquake activity and earthquake effects, and for reducing loss of life and property from earthquake disasters. Rapid dissemination of postearthquake information about shaking effects can promote situational awareness, benefiting residents of seismically active regions by allowing rapid mobilization of emergency response, at the level appropriate for the need.

\section{ANSS Products and Tools}

The ANSS now provides postearthquake decisionmaking tools and routinely disseminates information to users who have a need for near real-time earthquake analysis.

This list is not intended to be a comprehensive treatment of ANSS postearthquake products. Rather it is a summary of ongoing developments deemed of interest to the public, the media, and those responding to earthquakes, be it from the critical lifeline, utility, government, emergency response, emergency coordination, recovery, planning, business continuity, and other relevant communities.

Following are tools recommended for various types of user categories. For each category, see the URLs associated with each of the products portrayed on the back of this information sheet for more detailed information.

\section{Earthquake Information User Categories:}

\section{General Public and Media}

Latest Earthquakes

Earthquake Notification Service (ENS)

Real-time Feeds and Data

Did You Feel It?

ShakeMaps

Seismogram Displays

\section{Emergency Responders and Managers, Disaster} and Business Continuity Planners and Coordinators

Earthquake Notification Service (ENS)

Real-time Feeds and Data

ShakeMap

CISN (California Integrated Seismic Network)

Display

Prompt Assessment of Global Earthquakes

for Response (PAGER)

\section{Critical Lifeline and Utility Operators}

All of the above, plus ShakeCast 


\section{ANSS Earthquake Information Products and Tools}
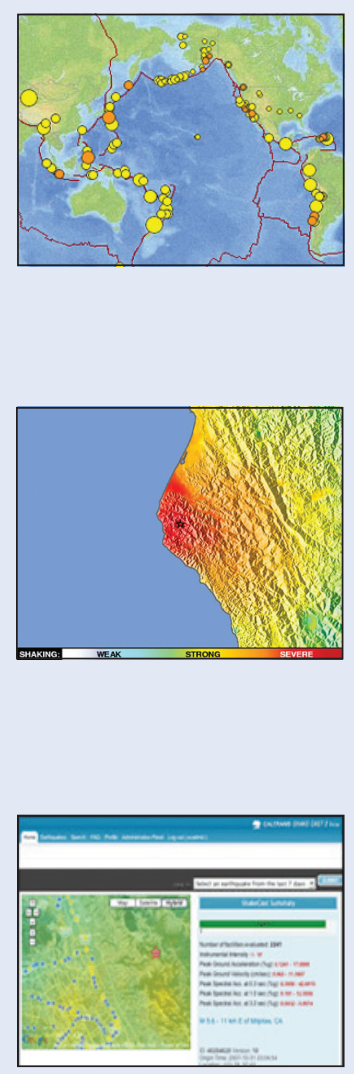

\section{ShakeCast}

Automated ShakeMap delivery, damage assessment, and notification for critical lifeline operators. http://earthquake.usgs.gov/research/ software/shakecast/

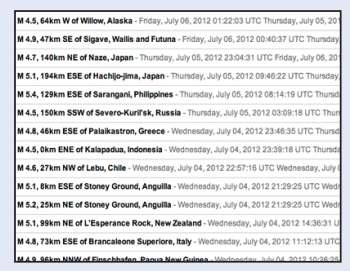

\section{Real-time Feeds and Data}

Real-time earthquake data in a variety of formats including RSS, CAP, CSV, and KML. http://earthquake.usgs.gov/ earthquakes/feed/

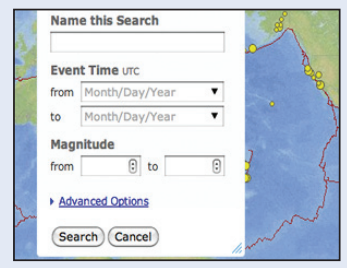

\section{Earthquake Data}

Catalog search, recent and historic earthquake archive, "Top 10" lists, scientific data, and so on. http://earthquake.usgs.gov/ earthquakes/eqarchives/

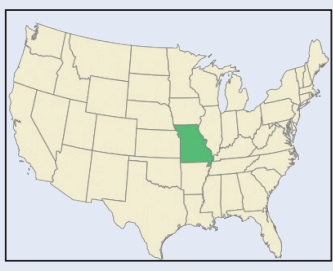

\section{Info by Region}

Pick a State or a country and find out about historical earthquakes, seismic hazard, local agencies, and more. http://earthquake.usgs.gov/ earthquakes/region.php

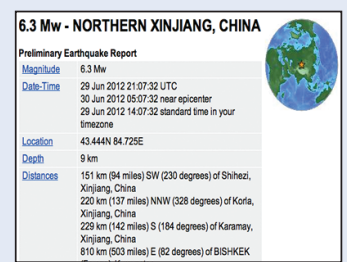

\section{Earthquake Notification Service (ENS)}

Customizable earthquake information automatically sent to your wireless device or email account.

https://sslearthquake.usgs.gov/ens/

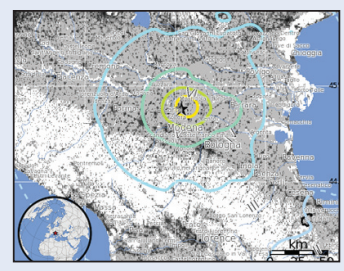

\section{PAGER}

Estimates of population exposure, fatalities, and impact on infrastructure to significant earthquake shaking anywhere in the world within minutes. http://earthquake.usgs.gov/pager/

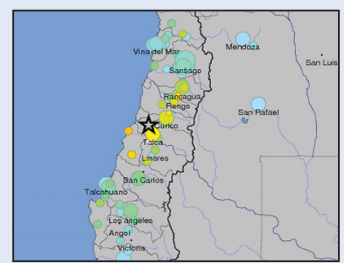

\section{Did You Feel lt?}

Citizen-science webpage where shaking intensity maps are created by the people who felt the earthquake. http://earthquake.usgs.gov/dyfi/

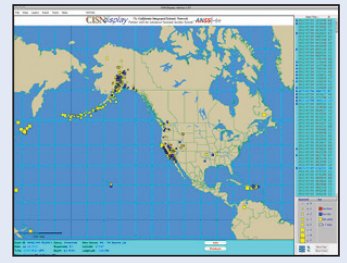

\section{CISN Display}

Downloadable software to visualize and receive notifications for seismicity anywhere in the world on your computer. http://www.cisn.org/software/ cisndisplay.html

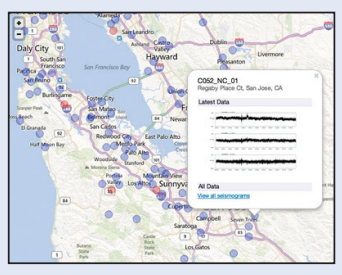

\section{NetQuakes}

Urban area seismic network instruments hosted by volunteers to provide dense ground motion data for various studies. http://earthquake.usgs.gov/ monitoring/netquakes/

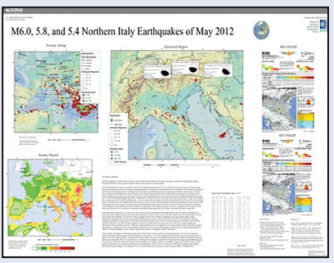

\section{Earthquake Summary Posters}

Posters created quickly after a significant earthquake with images and text about the seismic background of the area.

http://earthquake.usgs.gov/ earthquakes/eqarchives/poster/ 